\title{
Entrepreneurial ecosystems in an interconnected world: emergence, governance and digitalization
}

\author{
Ricarda B. Bouncken ${ }^{1}\left[\right.$ ] Sascha Kraus ${ }^{2}$ (i)
}

Received: 30 December 2020 / Accepted: 11 January 2021 / Published online: 26 January 2021

(c) The Author(s) 2021

\begin{abstract}
Achieving and sustaining growth depends on the effective work of multiple and interconnected actors - such as e.g. governments, the private sector, society, universities, entrepreneurs and many others-who build an ecosystem, i.e. a social and economic environment for innovative and entrepreneurial endeavors. The underlying idea is that firms do not just compete with each other through well-developed standalone strategies to achieve advantages over their rivals, uniquely relying on their own resources, knowledge, and capabilities, but rather base their business models on shared resources, network externalities, knowledge spill-overs, local endowments, and governmental support. This introductory article offers a wide array of topics, methods and fields of application within the field of entrepreneurial ecosystems as well as a theorizing about potential fruitful future areas of research within the field, concentrating on legitimation and identification processes in ecosystems, possibly culminating towards a meta-identity of the ecosystem.
\end{abstract}

Keywords Entrepreneurship · Entrepreneurial · Innovation · Ecosystems · Digitalization

JEL Classification $\mathrm{M} 1 \cdot \mathrm{M} 10 \cdot \mathrm{M} 19 \cdot \mathrm{M} 20$

Ricarda B. Bouncken

bouncken@uni-bayreuth.de

Sascha Kraus

sascha.kraus@zfke.de

1 Chair for Strategic Management and Organisation, University of Bayreuth, Prieserstraße 2, 95444 Bayreuth, Germany

2 Faculty of Economics and Management, Free University of Bozen-Bolzano, 39100 Bolzano, Italy 


\section{Motivation}

Achieving and sustaining growth and entrepreneurship depends on the effective work of multiple and interconnected actors, such as e.g. governments, the private sector, society, universities, entrepreneurs, and many others (Acs et al. 2016; Ferreira et al. 2019). Such ecosystems increasingly attract research and managerial attention (Alvedalen and Boschma 2017). Ecosystem research has considered business, innovation, and, more recently, entrepreneurial ecosystems (Jacobides et al. 2018). An entrepreneurial ecosystem is the social and economic environment affecting local or regional entrepreneurship (Acs et al. 2017; Roundy et al. 2017). The underlying idea is that firms do not just compete with each other through well-developed stand-alone strategies to achieve advantages over their rivals, uniquely relying on their own resources, knowledge, and capabilities, but rather base their business models on shared resources, network externalities, knowledge spill-overs, local endowments, and governmental support (Audretsch et al. 2019).

The idea of ecosystems received increased attention in business studies in the last decade (e.g. Jacobides et al. 2018), and is particularly important for improving the legitimacy and development of new ventures (e.g. Laamanen et al. 2018). The liabilities of new ventures might lessen when ventures enter or form ecosystems in which they can exchange ideas, knowledge, and resources, while also improving the legitimacy evaluations of their audiences (e.g. resource providers or customers). However, there is still sparse evidence how entrepreneurial ecosystems develop and operate and in which ways they influence venture performance. This special issue of the Review of Managerial Science contributes eight different theoretical and empirical studies that aim to advance the research field of entrepreneurial ecosystems.

In addition to these contributions, we develop thoughts on the coupling in entrepreneurial ecosystems and on legitimation and identification processes in ecosystems. So far, only little is known about the legitimation process of ventures in ecosystems, especially when those operate in emerging digital categories and how the ecosystem shapes identification processes.

In the following, we will first provide the theoretical and definitional background on entrepreneurial vs. innovation ecosystems, two widely overlapping concepts. Subsequently, we explain the contributions of the studies in this special issue. At last, we theorize and develop propositions about the coupling in entrepreneurial ecosystems, legitimation processes, and how identification processes might evolve towards a meta-identity of the ecosystem.

\section{Theoretical background}

The concept of an ecosystem originally stems from the field of biology, describing an interactive system of living organisms within their physical environment (Cavallo et al. 2019). In a similar vein, an entrepreneurial ecosystem describes a "set of interdependent actors and factors coordinated in such a way that they enable productive entrepreneurship within a particular territory" (Stam 2015, p. 
$5)$. The idea of the entrepreneurial ecosystem thus introduces ecological thought into the human socioeconomic order (Kang et al. 2019). Entrepreneurial ecosystems can operate at multiple levels (e.g. municipal, regional, national, cross border) and within multiple sectors (e.g., health care, education, new materials, and technologies, environmental projects). An entrepreneurial ecosystem is made up of different actors, relationships and resources e.g. within innovation networks and knowledge clusters who all play a role in taking their innovative idea to transformative impact at scale (Stam and Elfring 2008; Carayannis and Campbell 2009).

The effectiveness of each part within the ecosystem is moderated by other parts of the system (e.g., entrepreneurs depend on being able to access financing). A change to one part of the entrepreneurial ecosystem leads to changes in other parts of the ecosystem, such as e.g. an increase in Internet connectivity and speed-such as the upcoming $5 \mathrm{G}$ broadband connections-will accelerate the design and testing of new technologies. Especially the evolution and growth of the Internet has made our world truly interconnected and has enabled a plethora of innovative technologies, applications, products or services (Bouncken et al. 2020d). Local, regional, and international connects between actors can be enhanced by the digital technologies (Kraus et al. 2019; Mudambi et al. 2018). The ties between the resources and actors in creating these innovations can be compared to the interdependent and coevolving species in an ecological system. Recent advancements in information and communication technologies that foster an ongoing digitalization process (Newell and Marabelli 2015) offer new business opportunities and impose new challenges on firms (Laudien et al. 2018). Making use of the given market opportunities requires the development of digital knowledge and also calls for redesigning or innovating business models (Tallman et al. 2018; Sussan and Acs 2017; Kraus et al. 2020; Bouncken and Barwinski 2020). Ecosystems might use digital technologies for their inter-firm coupling and for complementarities of technologies among firms. Hence, especially the recent digital push encourages firms to strategically operate in ecosystems accessing complementary resources and pursuing legitimation using digital media and platforms. Digitalization allows fast feedback and autonomous digital processes while also enabling a more active role of customers shaping the demand (Dedehayir et al. 2016; Moore 1996; Kraus et al. 2019).

Recent research accordingly suggests that the ecosystem concept is gaining increasing importance particularly in high-tech industries where coopetition and open innovation activities are conducted around digital platforms where direct relationships may not exist between its major complementors (Hannah and Eisenhardt 2018; Kraus et al. 2018). More specifically, previous research has demonstrated the high importance of innovation ecosystems for new technology creation and growth (Adner and Kapoor 2016, 2010; Brusoni and Prencipe 2013; Jacobides et al. 2018; Laamanen et al. 2018; Vargo et al. 2015). Considering the developmental processes and the search for creative solutions and their implementation among different ventures in an ecosystem, there is a high definitional overlap among entrepreneurial and innovation ecosystems. Ventures that form or consider entrepreneurial ecosystems search for improving their resource base, similar to innovation ecosystems (Adner and Kapoor 2010; Brusoni and Prencipe 2013; Jackson 2011). Entrepreneurial 
ecosystems, in a similar way than to innovation ecosystems, enable the collaborative sourcing of knowledge, technology, and customer relationships (Adner 2017; Adner and Kapoor 2010; Jacobides et al. 2017). Yet, the focus of entrepreneurial ecosystems lies more on the early stages of a venture, including the founding process considering early focal entrepreneurial ventures in the system and the development of the entrepreneurial ecosystem as an entity.

Besides the numerous advantages, entrepreneurial ecosystems similar to innovation ecosystems might improve the resource access and the legitimacy of their members, but also bear high dynamics of roles, membership change, and changing logics (Adner 2006; Adner and Kapoor 2010, 2016; Kapoor and Lee 2013; Davis 2016).

The concept of entrepreneurial ecosystems also has overlaps with the cluster concept (e.g., Scott et al. 2019). Yet the latter concentrates on improving regional competitiveness and economic performance by co-location of businesses, e.g. in terms of productivity, innovation, or entrepreneurship (Dedehayir et al. 2016). Entrepreneurial ecosystems specifically overlap with clusters of new firms aiming on the progressing with specific technologies. Yet, ventures in entrepreneurial ecosystems do not necessarily need to operate in the same geographical location, which clusters address. Entrepreneurial ecosystems also have overlaps with young ventures in incubators or accelerators. Yet, ventures in incubators or accelerators, firms do not necessarily collaborate, so that their fate is not necessarily connected to the system. In addition, while incubators or accelerators are defined by the vicinity of their members, entrepreneurial ecosystems might span different locations. Their connection might be purely virtual (i.e. in platforms) or personal and virtual through linkages among persons or organizations across locations (Mudambi 2008).

Entrepreneurial ecosystems might develop or concentrate on a local or regional environment. Yet, the boundary of the entrepreneurial ecosystem as for the innovation ecosystem is not the geographical location but instead the "collective functionality' (Dedehayir et al. 2016, p. 2). This means that ventures do not need to be located in vicinity to each other. Instead, the new ventures operate in different locations only through functional correspondence, i.e. in a virtual location of a platform. Entrepreneurial ecosystems mean that the performance of ventures is strongly tied to the shared fate of the ecosystem as a whole (Iansiti and Levien 2004). Entrepreneurial ecosystems can mainly include small and new firms (Singh et al. 1986). Yet, large firms or investors who provide financial resources and advice might operate as well in the systems. In addition, huger incumbents might provide some technology to entrepreneurial ecosystems. Besides the benefits in terms of resource exchanges, entrepreneurial ecosystems can compensate for low reputation, firm-level smallness and newness, and low category legitimacy. These all complicate accessing critical resources for innovation and venture progress and often are needed for the development of digital technologies (Martens et al. 2007).

\section{Studies of entrepreneurial ecosystems in this issue}

This special issue entails eight contributions from the field of entrepreneurial ecosystems. 
It opens with overview study on the field. In their paper, "Entrepreneurial ecosystems and networks: A literature review and research agenda", Fernandes and Ferreira (2020) systematically review the literature on entrepreneurial ecosystems and networks by using bibliographic coupling of documents. As a result, they grouped the literature into four topic clusters: (1) Context and Cooperation; (2) Established Networks; (3) Challenges to the Affirmation of Minorities; and (4) Formal Structures. Their additional analysis of keywords co-occurrence furthermore revealed the most important literature trends on the topic of entrepreneurial ecosystems and networks: (1) innovation and dynamics: actors and norms; (2) performance, knowledge, and entrepreneurship; (3) technology and firms which might serve as a basis for future research on the topic.

In the article, "Towards a network-based view of effective entrepreneurial ecosystems", Scott et al. (2020) provide a conceptualization of how effective entrepreneurial ecosystems evolve and develop using a three-longitudinal and mixed-method ethnography. The authors suggest that prior static treatments of how entrepreneurial ecosystems emerge have overlooked the necessity to develop inter-organizational ties, behaviors, and the governance mechanisms to maintain the vibrancy, vitality, and wealth creation of the ecosystem. Using a network-based theoretical lens, the study sheds light on relational and governance mechanisms that underpin valuable and quality interactions with entrepreneurial ecosystems and the change that occurs during ecosystem evolution phases. The study suggests that ecosystems, relational configurations, and governance evolve in a cyclical and critical junctures pattern. The study also recommends that further studies into ecosystem development should examine the nature of relational behaviors, structural mechanisms, and content in conjunction, rather than in isolation, to further evidence of the underpinning mechanisms fueling their activities.

Endres et al. (2020) present "Digital innovation management for entrepreneurial ecosystems: Services and functionalities as drivers of innovation management software adoption". The authors highlight the digitalization of innovation processes for Entrepreneurial Ecosystems in their study. They use survey data from 199 innovation managers to empirically examine the factors influencing the adoption of Innovation Management Software. The findings from this study are important for helping managers, consultants, entrepreneurs, and developers to choose and leverage the right options for improving the adoption of IT tools in the New Product Development (NPD) process and therefore increase NPD performance and thus also promote entrepreneurial ecosystems.

In their contribution "The digital transformation of a traditional market into an entrepreneurial ecosystem", Song et al. (2020) analyze how the adoption of Information and Communication Technologies (ICT) brings about a traditional ecosystem to become an entrepreneurial one. Building on the case of a traditional wholesale fruit market in China, the authors propose a model to understand how some of the main mechanisms and outcomes of e-commerce (transaction costs; marketing channel power; business scope and network effects; value creation and business model innovation) enable productive entrepreneurship in a traditional market, leading to an entrepreneurial ecosystem. 
Bichler et al. (2020) explore how family entrepreneurs' embeddedness drives an entrepreneurial ecosystem as a regional context for innovation. Building on qualitative research from the hospitality context and the pattern matching approach, the authors distill the EEE framework and expand the understanding of (1) horizontal embeddedness in the economic and socio-political environment, their (2) vertical embeddedness in industry regimes, in particular the family, and their (3) spatial embeddedness in the region for value creation. The implications show that incorporating the social fabric is particularly important in regional entrepreneurial ecosystems and the study also proposes five propositions for future regional entrepreneurial ecosystem research.

In the next contribution, "Deconstructing the ivory tower: Identifying challenges of ecosystem partnerships", Bacon and Williams (2020) use a fuzzy-set qualitative comparative analysis (fsQCA) to ascertain the key challenges affecting ecosystem management within university-industry partnerships. Collaboration between industry and academia necessitates the management of entrepreneurial dynamics within ecosystem contexts. However, such partnerships perpetuate numerous challenges that, without effective management, can impact upon the ecosystem as a whole. The study's findings confirm multiple, mutually exclusive pathways to ineffective ecosystem management, grounded upon distinct combinations of conditions.

In the next contribution, "Species in the wild: A typology of innovation ecosystems", Klimas and Czakon (2020) explore and develop typology of innovation ecosystems. Based on findings from in-depth review of prior systematic literature reviews, the authors identify five aggregate typology categories and 14 criteria that allow to distinguish 50 different types of innovation ecosystems. Aggregate categories include: (1) the genesis and existence of IE; (2) the structure of IE; (3) the leading innovation focus within IE; (4) the range of IE, and (5) the performance of IE. This typology framework clarifies current understanding of innovation ecosystems, and, the delineating typology criteria bring us closer to the development of their operationalization and measurement.

As we have learned, innovation is the one of the main motive forces of entrepreneurial ecosystems. However, most studies examine the context wherein innovation is directly undertaken by entrepreneurs within the industry. The context where the innovation driving the industry arises from outside its boundaries has received little attention. Thus, Berman et al. (2020) examine in their final article of this issue, "Innovation and entrepreneurial ecosystems: Fintech in the financial services industry", the role of Fintech in the U.S. financial services industry. Their study shows that such innovation has had an asymmetric effect, strengthening start-ups at the expense of large incumbents, increasing the rate of entrepreneurial entry. This is opposite of the pattern documented for innovation that arises from within industry boundaries and suggests an interesting new avenue for research. 


\section{Developing directions for future research on entrepreneurial ecosystems}

\subsection{Coupling in entrepreneurial ecosystems}

Often entrepreneurial ecosystems develop around a focal entrepreneur who collaborates with others to improve resource endowments and reputation. Entrepreneurial ecosystems might support financial resources, advice, knowledge, but also tangible and intangible constituents as components or complements to the offering of the focal venture of the system. The greater the offering of the focal unit depends on components or complements from others, the greater is the need for coupling among the members. Entrepreneurial ecosystems explain collaboration between heterogeneous ventures that have different functionalities for entrepreneurship and innovation, e.g. where suppliers provide key technologies or inputs and other organizations deliver complementary products and where other new ventures, support organizations (e.g., business angles or supporters), as well as customers might take an active role in shaping the offerings of the ventures and on the system level (Dedehayir et al. 2016; Jacobides et al. 2018; Moore 1996).

As for innovation ecosystems, the emergence of entrepreneurial ecosystems needs coupling between the members, mainly of the ventures that exchange ideas, technology, and resources (Orton and Weick 1990). Institutionalizations among the nodes of the ecosystem functionally couple the ventures' components or modules (Akaka and Vargo 2013; Adner and Kapoor 2016; Jacobides et al. 2017; Orton and Weick 1990). Ventures in an entrepreneurial ecosystem interact for exchanging ideas and knowledge but also for adjusting components or complements. Through the exchanges on ideas, knowledge, components, and complements, the ventures become dependent on each other's activities in different ways. At the same time, ventures in the ecosystem have to maintain autonomy (Adner and Kapoor 2016; Adner 2017; Jacobides et al. 2017; Moore 1996). Hence, seamless coupling is crucial for entrepreneurial ecosystems the greater the performance of the participating ventures is tied to the shared fate of the entrepreneurial ecosystem as a whole (Iansiti and Levien 2004).

Coupling might be receptive or tight among the ventures in an ecosystem. While receptive coupling is more trust based and informal, tight and more rigid coupling comes from adhering to formal rules that define the functions, performance, and information exchange among partners (Brusoni et al. 2009). Alliance research has already shown that the trust based coordination in ties might provide smooth exchanges of also tacit knowledge while the more formal coordination provides more control but less absorption of tacit knowledge components (Fredrich et al. 2019). Still, coupling does not characterize the degree of rivalry among collaborators (Bouncken et al. 2020c).

Given it's the young ventures that form and operate in an entrepreneurial ecosystem, there will be low levels of formal coordination among those young organizations. Hence, we expect soft and more receptive forms of coupling for entrepreneurial ecosystems while innovation ecosystems might apply tight and receptive forms of coupling. 
Proposition 1 Receptive coupling guides the coupling in entrepreneurial ecosystems rather than tight and formal coupling.

Considering that ecosystems base on membership and coupling highlights that to processes of institutionalization and legitimization are important for the development and functioning of entrepreneurial ecosystems (Akaka et al. 2017).

\subsection{Theorizing towards legitimacy in entrepreneurial ecosystems}

Gaining legitimacy is crucial for firms and their growth, especially when they have liabilities of smallness and newness, or when they operate in emerging digital categories that need to advance the category legitimacy (Durand and Khaire 2017; Navis and Glynn 2011). Especially ventures and ecosystems in emerging categories are confronted with high dynamics and unclear sources of legitimacy (Vergne and Wry 2014). The new ventures in emerging categories face strongest limitations by their own liabilities of smallness (Singh et al. 1986) and low category legitimacy which complicate acquiring critical resources (Martens et al. 2007). Hence the process of gaining legitimacy is important for ventures in an entrepreneurial ecosystem and for the ecosystem itself. Legitimacy captures different forms.

Most previous research categorizes socio-political-regulative, socio-politicalnormative, and cognitive legitimacy (e.g., Zimmerman and Zeitz 2002). Others emphasize normative vs. cognitive legitimacy (Zhao et al. 2018). We follow the categorization of cognitive and normative legitimacy. Audiences perceive firms as cognitively legitimate when they are recognized as one of us or "one of those" (Bitektine 2011; Aldrich and Fiol 1994; Suchman 1995). Normative legitimacy describes how strongly organizations are perceived as adhering to the norms and values of a community. In the pursuit of legitimacy, entrepreneurial ecosystems as a whole and/ or its members might concentrate on shaping either cognitive or normative legitimacy or both. In addition, ventures might address cognitive and normative legitimacy in their identities and convey them in the claims they make in their narratives.

Entrepreneurial ecosystems might be influenced by the legitimation effects of the category they operate in, but also by the legitimation processes that occur when an entrepreneurial ecosystem evolves. The entrepreneurial ecosystem might be subject to legitimation processes and thus gain legitimacy of its own.

Hence, ventures might purposefully select ecosystems that are coherent with their legitimacy concerns, i.e., those ecosystems that cohere with values, norms, and expectations of the venture and of those to be expected in the category. Legitimation does not just happen to organizations but might evolve by pursuing a strategic approach. Legitimation describes the process of building legitimacy (Zimmerman and Zeitz 2002). Developing and participation of ventures ecosystems allow using and even influencing the legitimacy evaluations of ventures' audiences.

There might be heterogeneous audiences that ventures and ecosystem need to consider in their legitimation efforts. Audiences in (entrepreneurial) ecosystems might relate to the inside and outside of the ecosystem, the levels of the ecosystem, and the different roles in ecosystems, and be connected with different founding 
stages and behaviors. The different levels of the ecosystem, the spill-overs from a focal organization, its reference to the ecosystem and, if applicable, the entrepreneurial ecosystem's own tactics (e.g., signaled by narratives of the ecosystem) shows the diversity of audiences for normative and cognitive legitimation.

Researchers have discussed how firms, especially new ventures can pursue conformity or try to stand out through distinctiveness and gain external resources (Navis and Glynn 2010; Täuscher et al. 2020). Firms might reach an optimal point where both demands are in balance (Zhao et al. 2017, 2018). Cognitive legitimacy might not be sufficient alone for the new ventures in ecosystems that have strong liabilities of resources and newness. Normative legitimacy and cognitive legitimacy might exist in a complementary relationship on both the venture and the ecosystem level.

Distinctiveness vs. conformity and the optimal level of distinctiveness has been discussed in the context of category membership so far. Yet, the question of distinctiveness and conformity is more complex with respect to ecosystems, because members not only have to consider their distinctiveness or conformity in a category, but also in the context of the ecosystem. The members of an entrepreneurial ecosystem might strive towards distinctiveness from each other or towards greater conformity of their components. Thus, entrepreneurial ecosystems can consist of members that might remain distinctive. Alternatively, following conformity, ventures might search for ways so that they potentially substitute components of each other and so become more similar e.g. by co-evolving capabilities and systems (Adner and Kapoor 2016; Adner 2017; Jacobides et al. 2017; Moore 1996). Via greater conformity, the ecosystem will find it easier to achieve coherent cognitive legitimacy as a whole. Hence, the components that form the 'Gestalt' of an entrepreneurial ecosystem can be less or more distinct or more conform to each other. We assume that ventures in entrepreneurial ecosystems can pursue a conformity or a distinctiveness pathway alternatively. Highly growing ecosystems might first develop a more coherent cognitive legitimacy and later become more disjunct while developing specific sublevel-distinctiveness.

Proposition 2 High growth entrepreneurial ecosystems will undergo coherence pressures first, and then develop towards more disjunct sublevel-distinctiveness, while ventures in low growth entrepreneurial ecosystems will remain more autonomous and distinct.

\subsection{Theorizing on identification processes in entrepreneurial ecosystems}

Coordination among firms in entrepreneurial ecosystems might be connected to identification processes that allow a more fluid and norm-based coordination (Schreyögg and Sydow 2010). Thus, softer coupling in entrepreneurial ecosystems might be based on shared identification processes, perhaps even some shared identification on the ecosystem level.

Identity is related to how an individual self is formed in a social context, but the self might transform from an individual to a group or a collective entity. 
Organizational members can form an intersubjective understanding by creating a seemingly objective reality, which transcended their individual and shared representations in a group. Such inter-subjective identity can become a taken-for-granted reality, which is not related to individual. It might be visible in goals, claims, and routines and other institutionalizations of an organization (Ashforth et al. 2011). The different individual and group based behavioral expectations influence evaluations in a group, organization, and society about what is define appropriate behavior (Burke 2003).

Identification process are powerful for new and young firms where few formal regulations demand fluid and joint value based coordination. Physical proximity and operating in a shared, even social emotionally laden environment (e.g. in incubators, makerspaces, or coworking-spaces) eases the inter-personal development of a shared identification (Bouncken et al. 2020b, 2020a). Shared identification assists the exchange of tacit knowledge even over spatial distance (Bouncken and Barwinski 2020). It has already been shown that identification in family firms can be a strong anchor for the coordination via values in family firms. Reay 2009 shows that contractions of individuals and groups in a family firm became resolved by a familybusiness meta-identity. Shepherd and Haynie 2009, regard to the meta-identity "as the set of behavioral expectations associated with the family role" (p. 1251), which resolves identity conflicts of their members. The family-business identity emerges over time and interacts with the business owner identity "as the set of behavioral expectations associated with the business owner role" (Shepherd and Haynie 2009, p. 1251) that might be mutually reinforcing. It can explain specific conflict resolutions and following opportunities.

Founders might follow specific identity types and coin their identity on the new venture. We assume that there are spill-over effects of identity among the founders in entrepreneurial ecosystems that might develop a shared identification within the entrepreneurial ecosystem. More shared identification processes also relate to the normative legitimation anchor and processes of ventures in entrepreneurial ecosystems.

The fluid coordination among ventures in an entrepreneurial ecosystem contributes to shared identification processes. Yet, ventures will not fully focus on the ecosystem identity and maintain their own, strongly founder-based identity. Hence, entrepreneurial ecosystems might combine venture and entrepreneurial ecosystem logics that members of the ecosystem use for identification processes. Strong growth processes and longer relationships bind members and develop a wake of a shared identity in the entrepreneurial ecosystem. This might be based on an amalgam of both venture and ecosystem identification. It can anchor and build a meta-identity of the ecosystem.

Proposition 3 Strong growth processes and long-term relationships among ventures in entrepreneurial ecosystems stimulate anchoring on a meta-identity of the ecosystem. 


\section{Conclusion}

Entrepreneurial ecosystems have recently gained more and more importance in the "real world", and research is proliferating on this topic. This special issues contributes conceptual and empirical research on the forefront of entrepreneurial ecosystems research. It deepens the understanding of ecosystems, actors and norms, delineating typology criteria, different forms of ecosystems, their relational and digital government mechanisms, paths for the development of ecosystems and how they can advance the development of start-ups compared to incumbent large firms. Entrepreneurial ecosystems do occur in different forms, using different governance mechanisms, which are again key to performance. Social relationships, norms, and trust are fundamental to entrepreneurial ecosystems, especially when they occur in a specific local or regional environment. Yet, the management of these systems benefits from a wider and efficient use of digital technology and technological tools while additionally allow strengthening the entrepreneurial orientation of an ecosystem and finding new innovative business models. Greater innovation in the system allows start-ups to proliferate in the system, thereby increasing the rate of entrepreneurial entry and activity. The social relationships and relational governance of an entrepreneurial ecosystem triggers identification processes among the firms in the ecosystem towards an ecosystem meta-identity. Those processes in turn can strengthen the relational governance of an entrepreneurial ecosystem. Future research might analyze legitimation processes on the venture and on the ecosystem level. In this vein, future research might analyze how optimal distinctiveness of a venture is influenced through operating in an entrepreneurial ecosystem, if optimal distinctiveness can exist on the ecosystem level, and which converging or distinction related factors influence this meta-level distinctiveness.

Funding Open Access funding enabled and organized by Projekt DEAL.

Open Access This article is licensed under a Creative Commons Attribution 4.0 International License, which permits use, sharing, adaptation, distribution and reproduction in any medium or format, as long as you give appropriate credit to the original author(s) and the source, provide a link to the Creative Commons licence, and indicate if changes were made. The images or other third party material in this article are included in the article's Creative Commons licence, unless indicated otherwise in a credit line to the material. If material is not included in the article's Creative Commons licence and your intended use is not permitted by statutory regulation or exceeds the permitted use, you will need to obtain permission directly from the copyright holder. To view a copy of this licence, visit http://creativecommons.org/licen ses/by/4.0/.

\section{References}

Acs ZJ, Audretsch DB, Lehmann EE, Licht G (2016) National systems of entrepreneurship. Small Bus Econ 46(4):527-535

Acs ZJ, Stam E, Audretsch DB, O'Connor A (2017) The lineages of the entrepreneurial ecosystem approach. Small Bus Econ 49(1):1-10 
Adner R (2006) Match your innovation strategy to your innovation ecosystem. Harvard Bus Rev 84(4):2-10

Adner R (2017) Ecosystem as structure: An actionable construct for strategy. J Manag 43(1):39-58

Adner R, Kapoor R (2010) Value creation in innovation ecosystems: How the structure of technological interdependence affects firm performance in new technology generations. Strateg Manag $\mathrm{J}$ 31(3):306-333

Adner R, Kapoor R (2016) Innovation ecosystems and the pace of substitution: re-examining technology S-curves. Strateg Manag J 37(4):625-648

Akaka MA, Vargo SL (2013) Technology as an operant resource in service (eco)systems. Inf Syst e-Bus Manag 12(3):367-384

Akaka MA, Vargo SL, Wieland H (2017) Extending the Context of Innovation: the Co-creation and Institutionalization of Technology and Markets. In: Russo-Spena T, Mele C, Nuutinen M (eds) Innovating in practice. Springer, Berlin, pp 43-57

Aldrich HE, Fiol CM (1994) Fools rush in? The institutional context of industry creation. Acad Manag Rev 19(4):645-670

Alvedalen J, Boschma R (2017) A critical review of entrepreneurial ecosystems research: towards a future research agenda. Eur Plan Stud 25(6):887-903

Ashforth BE, Rogers KM, Corley KG (2011) Identity in organizations: exploring cross-level dynamics. Organ Sci 22(5):1144-1156

Audretsch DB, Cunningham JA, Kuratko DF, Lehmann EE, Menter M (2019) Entrepreneurial ecosystems: economic, technological, and societal impacts. J Technol Transf 44(2):313-325

Bacon E, Williams M (2020) Deconstructing the ivory tower: Identifying challenges of ecosystem partnerships. Rev Manag Sci (in press)

Berman A, Mudambi R, Cano-Kollmann M (2020) Innovation and entrepreneurial ecosystems: fintech in the financial services industry. Rev Manag Sci (in press)

Bichler BF, Kallmuenzer A, Peters M, Petry T, Clauss T (2020) Regional entrepreneurial ecosystems: how family firm embeddedness triggers ecosystem development. Rev Manag Sci (in press)

Bitektine A (2011) Toward a theory of social judgments of organizations: the case of legitimacy, reputation, and status. Acad Manag Rev 36(1):151-179

Bouncken R, Barwinski R (2020) Shared digital identity and rich knowledge ties in global 3D printinga drizzle in the clouds? Glob Strategy J. https://doi.org/10.1002/gsj.1370

Bouncken RB, Kraus S, Martínez-Pérez JF (2020) Entrepreneurship of an institutional field: the emergence of coworking spaces for digital business models. Int Entrep Manag J 16(4):1465-1481

Bouncken R, Ratzmann M, Barwinski R, Kraus S (2020a) Coworking spaces: empowerment for entrepreneurship and innovation in the digital and sharing economy. J Bus Res 114:102-110

Bouncken RB, Aslam MM, Qiu Y (2020b) Coworking spaces: understanding, using, and managing sociomateriality. Bus Horiz 64(1):119-130

Bouncken RB, Fredrich V, Kraus S (2020c) Configurations of firm-level value capture in coopetition. Long Range Plan 53(1):101869

Brusoni S, Prencipe A (2013) The organization of innovation in ecosystems: problem framing, problem solving, and patterns of coupling. In: Adner R, Oxley JE, Silverman BS (eds) Collaboration and competition in business ecosystems. Emerald Group Publishing Limited, Bingley, pp 167-194

Brusoni S, Jacobides MG, Prencipe A (2009) Strategic dynamics in industry architectures and the challenges of knowledge integration. Eur Manag Rev 6(4):209-216

Burke PJ (2003) Relationships among multiple identities. In: Advances in identity theory and research. Springer, Boston, MA, pp 195-214

Carayannis EG, Campbell DF (2009) "Mode 3" and "Quadruple Helix": toward a 21st century fractal innovation ecosystem. Int J Technol Manage 46(3-4):201-234

Cavallo A, Ghezzi A, Balocco R (2019) Entrepreneurial ecosystem research: present debates and future directions. Int Entrep Manag J 15(4):1291-1321

Davis JP (2016) The group dynamics of interorganizational relationships: collaborating with multiple partners in innovation ecosystems. Adm Sci Q 61(4):621-661

Dedehayir O, Mäkinen SJ, Ortt RJ (2016) Roles during innovation ecosystem genesis: a literature review. Technol Forecast Soc Change 136:18-29

Durand R, Khaire M (2017) Where do market categories come from and how? Distinguishing category creation from category emergence. J Manag 43(1):87-110 
Endres, H., Hüsig, S. and Pesch, R. (2020) Digital innovation management for entrepreneurial ecosystems: Services and functionalities as drivers of innovation management software adoption. Rev Manag Sci (in press)

Fernandes, A.J. and Ferreira, J.M. (2020) Entrepreneurial ecosystems and networks: a literature review and research agenda. Rev Manag Sci (in press)

Ferreira JJM, Fernandes CI, Kraus S (2019) Entrepreneurship research: mapping intellectual structures and research trends. RMS 13(1):181-205

Fredrich V, Bouncken RB, Kraus S (2019) The race is on: Configurations of absorptive capacity, interdependence and slack resources for interorganizational learning in coopetition alliances. J Bus Res 101:862-868

Hannah DP, Eisenhardt KM (2018) How firms navigate cooperation and competition in nascent ecosystems. Strateg Manag J 39(12):3163-3192

Iansiti M, Levien R (2004) The keystone advantage: what the new dynamics of business ecosystems mean for strategy, innovation, and sustainability. Harvard Business Press, Harvard

Jackson DJ (2011) What is an innovation ecosystem. National Science Foundation, Arlington, VA, pp $1-11$

Jacobides MG, Cennamo C, Gawer A (2017) Towards a theory of business ecosystems

Jacobides MG, Cennamo C, Gawer A (2018) Towards a theory of ecosystems. Strateg Manag J 39(8):2255-2277

Kang Q, Li H, Cheng Y, Kraus SJKMR, Practice (2019) Entrepreneurial ecosystems: analysing the status quo', 1-13

Kapoor R, Lee JM (2013) Coordinating and competing in ecosystems: how organizational forms shape new technology investments. Strateg Manag J 34(3):274-296

Klimas P, Czakon W (2020) Species in the wild: a typology of innovation ecosystems. Rev Manag Sci (in press)

Kraus S, Meier F, Niemand T, Bouncken R, Ritala P (2018) In search for the ideal coopetition partner: an experimental study. RMS 12(4):1025-1053

Kraus S, Palmer C, Kailer N, Kallinger FL, Spitzer J (2019) Digital entrepreneurship: a research agenda on new business models for the twenty-first century. Int J Entrepreneurial Behav Res 25(2):353-375

Kraus S, RoigTierno N, Bouncken RB (2019) Digital innovation and venturing: an introduction into the digitalization of entrepreneurship. Rev Manag Sci 13:519-528

Kraus S, Filser M, Puumalainen K, Kailer N, Thurner S (2020) Business model innovation: a systematic literature review. Int J Innov Technol Manag 17(6):2050043

Laamanen T, Pfeffer J, Rong K, Van de Ven A (2018) Editors' Introduction: Business models, ecosystems, and society in the sharing economy. Acad Manag Discov 4(3):213-219

Laudien SM, Bouncken R, Pesch R (2018) Understanding the acceptance of digitalization-based business models: a qualitative-empirical analysis'. Acad Manag Glob Proc 2018:104

Martens ML, Jennings JE, Jennings PD (2007) Do the stories they tell get them the money they need? The role of entrepreneurial narratives in resource acquisition. Acad Manag J 50(5):1107-1132

Moore JF (1996) The death of competition: leadership and strategy in the age of ecosystems. HarperBusiness, New York

Mudambi R (2008) Location, control and innovation in knowledge-intensive industries. J Econ Geogr 8(5):699-725

Mudambi R, Li L, Ma X, Makino S, Qian G, Boschma R (2018) Zoom in, zoom out: geographic scale and multinational activity. J Int Bus Stud 49:929-941

Navis C, Glynn MA (2010) How new market categories emerge: temporal dynamics of legitimacy, identity, and entrepreneurship in satellite radio, 1990-2005. Adm Sci Q 55(3):439-471

Navis C, Glynn MA (2011) Legitimate distinctiveness and the entrepreneurial identity: influence on investor judgments of new venture plausibility. Acad Manag Rev 36(3):479-499

Newell S, Marabelli M (2015) Strategic opportunities (and challenges) of algorithmic decision-making: A call for action on the long-term societal effects of 'datification.' J Strateg Inf Syst 24(1):3-14

Orton JD, Weick KE (1990) Loosely coupled systems: a reconceptualization. Acad Manag Rev 15(2):203-219

Reay T (2009) Family-business meta-identity, institutional pressures, and ability to respond to entrepreneurial opportunities. Entrep Theory Pract 33(6):1265-1270

Roundy PT, Brockman BK, Bradshaw M (2017) The resilience of entrepreneurial ecosystems. J Bus Ventur Insights 8:99-104 
Schreyögg G, Sydow J (2010) Crossroads—organizing for fluidity? Dilemmas of new organizational forms. Organ Sci 21(6):1251-1262

Scott S, Hughes M, Kraus S (2019) Developing relationships in innovation clusters. Entrep Reg Dev 31(1-2):22-45

Scott S, Hughes M, Ribeiro-Soriano . (2020) Towards a network-based view of effective entrepreneurial ecosystems. Rev Manag Sci (in press)

Shepherd D, Haynie JM (2009) Birds of a feather don't always flock together: identity management in entrepreneurship. J Bus Ventur 24(4):316-337

Singh JV, Tucker DJ, House RJ (1986) Organizational legitimacy and the liability of newness. Adm Sci Q 31(2):171-193

Song Y, Escobar OR, Arzubiaga U, De Massis A (2020) The digital transformation of a traditional market into an entrepreneurial ecosystem. Rev Manag Sci (in press)

Stam E (2015) Entrepreneurial ecosystems and regional policy: a sympathetic critique. Eur Plan Stud 23(9):1759-1769

Stam W, Elfring T (2008) Entrepreneurial orientation and new venture performance: the moderating role of intra-and extraindustry social capital. Acad Manag J 51(1):97-111

Suchman MC (1995) Managing legitimacy: strategic and institutional approaches. Acad Manag Rev 20(3):571-610

Sussan F, Acs ZJ (2017) The digital entrepreneurial ecosystem. Small Bus Econ 49(1):55-73

Tallman S, Luo Y, Buckley PJ (2018) Business models in global competition. Glob Strat J 8(4):517-535

Täuscher K , Bouncken R, Pesch R (2020) Gaining legitimacy by being different: optimal distinctiveness in crowdfunding platforms. Acad Manag J (in press)

Vargo SL, Wieland H, Akaka MA (2015) Innovation through institutionalization: a service ecosystems perspective. Ind Mark Manage 44:63-72

Vergne JP, Wry T (2014) Categorizing categorization research: review, integration, and future directions. J Manage Stud 51(1):56-94

Zhao EY, Fisher G, Lounsbury M, Miller D (2017) Optimal distinctiveness: broadening the interface between institutional theory and strategic management. Strateg Manag J 38(1):93-113

Zhao EY, Ishihara M, Jennings PD, Lounsbury M (2018) Optimal distinctiveness in the console video game industry: an exemplar-based model of proto-category evolution. Organ Sci 29(4):588-611

Zimmerman MA, Zeitz GJ (2002) Beyond survival: achieving new venture growth by building legitimacy. Acad Manag Rev 27(3):414-431

Publisher's Note Springer Nature remains neutral with regard to jurisdictional claims in published maps and institutional affiliations. 